\title{
On How Social Networking Sites Affect Online Consumer Purchase Intention
}

\author{
Victor K. Y. Chan ${ }^{1, \text { a }}$, Carolina Lei ${ }^{1}$, Sabrina U. I. Leong ${ }^{1}$, Sam K. C. $\mathrm{Ng}^{1}$, Ken \\ U. K. Wong ${ }^{1}$ \\ ${ }^{1}$ School of Business, Macao Polytechnic Institute, Macao, China \\ aemail: vkychan@ipm.edu.mo
}

Keywords: Social Networking Sites; SNS; Purchase Intention; Technology Acceptance Model; Peer Influence; Electronic Word-of-Mouth; eWOM; Attitude

\begin{abstract}
In view of the prevalence of social networking sites (SNSs) among Internet users and such sites' use in commercial marketing and sales, there has been growing interest in both academia and industry in the study on the effects of SNSs and its various aspects on consumer behavior, inclusive of online consumer purchase intention. In this paper, the effects of the Technology Acceptance Model's constructs, peer influence, and electronic Word-of-Mouth in the context of SNS on online consumer purchase intention are proposed and subsequently tested statistically.
\end{abstract}

\section{Introduction}

People heavily rely on social networking sites (SNS) when making purchasing decisions nowadays [1]. Previous researches establish that in the context of SNSs, constructs of the Technology Acceptance Model (TAM) [2], which predicts users' attitude towards a new technology and delineates the way its acceptance leads to intention of use and effective use [3] [4], are correlated with consumers' purchasing decision on SNSs [5]. Likewise, the literature reveals that peer influence [6] affects purchasing decision [7] as does Electronic Word of Mouth (eWOM) [8] [9].

In this paper, the effects of the TAM constructs, peer influence, and eWOM in the context of SNSs on online consumer purchase intention are proposed and subsequently tested statistically.

\section{The Theoretical Framework and Hypotheses}

Figure 1 shows our theoretical framework whilst the null hypotheses $\mathrm{H}_{1}$ to $\mathrm{H}_{6}$ are enumerated below it. Constructs like "perceived ease of use," "perceived usefulness," etc. in Figure 1 are also made self-explanatory by the hypotheses.

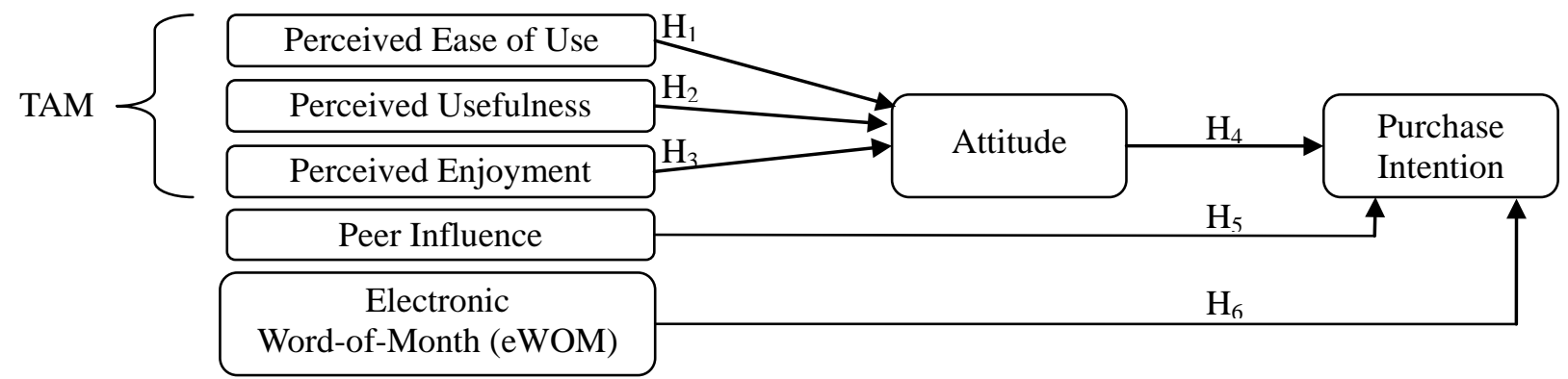

Fig.1. The theoretical framework

$\mathbf{H}_{1}$ : A person's "perceived ease of use" of SNSs is not correlated with his/her "attitude" towards SNSs.

$\mathbf{H}_{2}$ : A person's "perceived usefulness" of SNSs is not correlated with his/her "attitude" towards SNSs.

$\mathbf{H}_{3}$ : A person's "perceived enjoyment" of SNSs is not correlated with his/her "attitude" towards SNSs.

$\mathbf{H}_{4}$ : A person's "attitude" towards SNSs is not correlated with his/her "purchase intention" on 
SNSs.

$\mathbf{H}_{5}$ : "Peer influence" on a person is not correlated with his/her "purchase intention" on SNSs.

$\mathbf{H}_{6}$ : "eWOM" on SNSs experienced by a person is not correlated with his/her "purchase intention" on SNSs.

\section{Methodology}

A quantitative methodology was adopted with 300 questionnaires having been distributed to undergraduate students at Macao Polytechnic Institute, ending up with 264 valid questionnaires having been collected or a response rate of $88 \%$. Each questionnaire comprised five sets of items for the student respondent to rate on a 7-point Likert scale, each set respectively being

- adapted from TAM [2] to gauge the respondent's "perceived ease of use," "perceived usefulness," and "perceived enjoyment" of SNSs,

- based on [10] to evaluate the respondent's "attitude" towards SNSs,

- based on [11], [9] to measure the "peer influence" on the respondent,

- adapted from [11] to assess the "eWOM" on SNSs experienced by the respondent, and

- adapted from [12] to appraise the respondent's "purchase intention" on SNSs.

In other words, each of the constructs "perceived ease of use," "perceived usefulness," etc. in Figure 1 was operationalized through each respondent's ratings of a few items in each questionnaire. The Cronbach's $\alpha$ of each of these constructs is 0.770 minimum, indicating the acceptable internal consistency of all of them given such operationalization.

Subsequently, principal component analysis was applied to attempt to extract a small number of, preferably one, component(s) out of the respondents' ratings of the relatively large number of items for each construct such that a small number of respondent-specific component score(s) corresponding to the extracted component(s) could be derived to represent each respondent's rating of the construct. It turned out that one single component was extracted from and thus one single component score was derived to represent each of the constructs in Figure 1 except that two components were extracted from and thus two component scores were derived to represent the construct "peer influence." Therefore, all component scores so derived were named the same as their corresponding constructs except that the two components scores derived for the construct "peer influence" were dubbed "informational influence" and "normative Influence" based on the ensuing component loadings and the corresponding items' nature. Consequently, the theoretical framework was remodeled as in Figure 2, and null hypothesis $\mathrm{H}_{5}$ was transformed into two hypotheses $\mathrm{H}_{5 \mathrm{~A}}$ and $\mathrm{H}_{5 \mathrm{~B}}$ as stipulated underneath Figure 2 whereas other hypotheses remained the same. It is noteworthy that "perceived ease of use," "perceived usefulness," etc. in Figure 2 and all associated hypotheses $\mathrm{H}_{1}, \ldots, \mathrm{H}_{4}, \mathrm{H}_{5 \mathrm{~A}}, \mathrm{H}_{5 \mathrm{~B}}$ and $\mathrm{H}_{6}$ are component scores as opposed to the constructs in Figure 1.

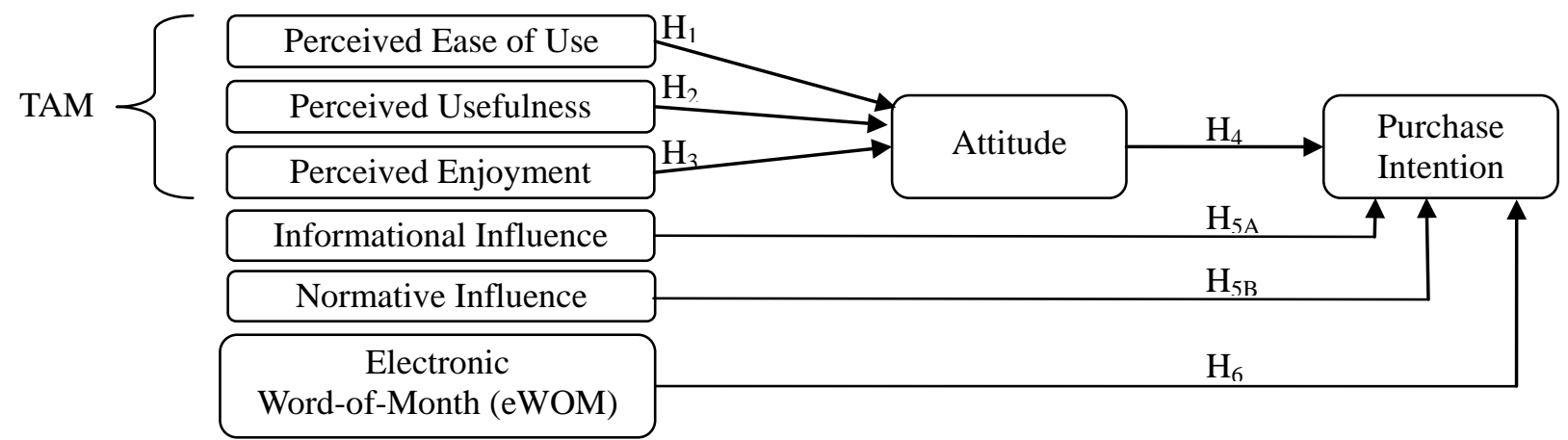

Fig.2. The remodeled theoretical framework

$\mathbf{H}_{5 \mathrm{~A}}$ : "Informational Influence" on a person is correlated with his/her "purchase intention" on SNSs. $\mathbf{H}_{5 \mathbf{B}}$ : "Normative Influence" on a person is correlated with his/her "purchase intention" on SNSs.

Then, regression analysis was applied to test null hypotheses $\mathrm{H}_{1}, \ldots, \mathrm{H}_{4}, \mathrm{H}_{5 \mathrm{~A}}, \mathrm{H}_{5 \mathrm{~B}}$ and $\mathrm{H}_{6}$ and determine whether the correlation, if any, underlying each such hypothesis was positive or negative. 


\section{Findings}

Table 1 depicts the findings from the regression analysis where the hypothesis tests were performed at the $5 \%$ significance level.

Table1. Findings: regression analysis

\begin{tabular}{|c|c|c|}
\hline Null Hypothesis & Reject/ Accept & Positive (+)/ Negative (-) \\
\hline $\mathrm{H}_{1}$ & Accept & Not applicable \\
\hline $\mathrm{H}_{2}$ & Reject & + \\
\hline $\mathrm{H}_{3}$ & Reject & + \\
\hline $\mathrm{H}_{4}$ & Reject & + \\
\hline $\mathrm{H}_{5 \mathrm{~A}}$ & Reject & Not applicable \\
\hline $\mathrm{H}_{5 \mathrm{~B}}$ & Accept & + \\
\hline $\mathrm{H}_{6}$ & Reject & + \\
\hline
\end{tabular}

The regression analysis also revealed that "perceived ease of use" was positively and directly correlated with "purchase intention" but not through "attitude” as a mediator.

\section{Conclusion}

A person's "perceived ease of use" of SNSs, peers' "informational influence on the person, and eWOM on SNS experienced by the person are positively and directly correlated with his/her "purchase intention" on SNSs whilst a person's "perceived usefulness" and "perceived enjoyment" of SNSs are positively correlated with his/her "purchase intention" on SNSs via his/her "attitude" towards SNSs as a mediator.

The implications to electronic businesses are that their website designs must take into account ease of use, usefulness, and enjoyment in order to stand a better chance of success in online sales of products and services. Also, electronic businesses are supposed to take seriously the spread of opinions about their products and services among peer consumers in the form of eWOM or otherwise whereas norm formation among peer consumers does not seem to matter to online sales of products and services.

\section{References}

[1] Oliver Hinz, Bernd Skiera, Christian Barrot, Jan U. Becker. Seeding strategies for viral marketing: an empirical comparison [J]. Journal of Marketing, 2011 75(6) 55-71.

[2] Fred D. Davis. Perceived usefulness, perceived ease of use, and user acceptance of information technology [J]. MIS Quarterly, 1989 13(3) 319-340.

[3] Liaquat Hossain, Anjali de Silva. Exploring user acceptance of technology using social networks [J]. The Journal of High Technology Management Research, 2009 20(1) 1-18.

[4] Chin-Lung Hsu, Judy Chuan-Chuan Lin. Acceptance of blog usage: the roles of technology acceptance, social influence and knowledge sharing motivation [J]. Information \& Management, 2008 45(1) 65-74.

[5] Loredana Di Pietro, Eleonora Pantano. An empirical investigation of social network influence on consumer purchasing decision: the case of Facebook [J]. Journal of Direct, Data and Digital Marketing Practice 2012 14(1) 18-29.

[6] Robert B. Cialdini, Melanie R. Trost. Social influence: social norms, conformity and compliance. In Daniel T. Gilbert, Susan T. Fiske, Gardner Lindzey (Ed), The Handbook of Social Psychology, 4th ed, 1998 1(2) 151-192.

[7] June Cotte, Stacy L. Wood. Families and innovative consumer behavior: a triadic analysis of sibling and parental influence [J]. Journal of Consumer Research 2004 31(1) 78-86. 
[8] Robert V. Kozinets, Kristine de Valck, Andrea C. Wojnicki, Sarah J.S. Wilner. Networked narratives: understanding word-of-mouth marketing in online communities [J]. Journal of Marketing, 2010 74(2) 71-89.

[9] Tao Sun, Seounmi Youn, Guohua Wu, Mana Kuntaraporn. Online word-of-mouth (or mouse): an exploration of its antecedents and consequences [J]. Journal of Computer-Mediated Communication, 2006 11(4) 1104-1127.

[10] Ji-Won Moon, Young-Gul Kim. Extending the TAM for a World-Wide-Web context [J]. Information \& Management, 2001 38(4) 217-230.

[11] Leisa Reinecke Flynn, Ronald E. Goldsmith, Jacqueline K. Eastman. Opinion leaders and opinion seekers: two new measurement scales [J]. Journal of the Academy of Marketing Science 1996 24(2) 137-147.

[12] David Gefen. E-commerce: the role of familiarity and trust [J]. Omega, 2000 28(6) 725-737. 